\title{
ANALISIS DISKRIMINAN UNTUK MENENTUKAN INDIKATOR GARIS KEMISKINAN
}

\author{
(Discriminant Analysis to Determine Poverty Line Indicators)
}

\author{
Dadang Sukandar ${ }^{1 *}$, Nani Sufiani Suhanda ${ }^{2}$, Leily Amalia ${ }^{1}$, dan Khairunisa ${ }^{3}$ \\ ${ }^{1}$ Departemen Gizi Masyarakat, Fakultas Ekologi Manusia (FEMA), IPB \\ Tel: 0251-8628304/8621258; Faks: 0251-8625846/8622276. \\ 2 Pusat Pelatihan Manajemen dan Kepemimpinan Pertanian (PPMKP) Departemen Pertanian \\ 3 Program Studi Gizi Masyarakat dan Sumber daya Keluarga, Fakultas Pertanian (FAPERTA) IPB
}

\begin{abstract}
The objectives of this study are to: 1) determine poverty line gold standard of farmers, 2) compare the gold standard with existing poverty line i.e. Sajogyo, Central Bureau of Statistics, BKKBN, World Bank US \$ 1 and World Bank US \$2, and 3) derive poverty indicators. This research was conducted in Subang, West Java. As many as 522 farmer households were collected as sample through stratified random sampling with proportional allocation. Data collected include socio-economic, income, expenditure, food consumption, health, anthropometry, agriculture aspects and living cost component and their prices. The Gold Standard was obtained through distribution standard normal while poverty indicator was derived through discriminant analysis. The results show that the poverty line gold standard of farmer is Rp. 457,558/ capita/month which is equivalent to $2.29 \mathrm{gram}$ of gold/capita/month. Discriminant analysis give five indicators of poverty namely, number of households member, husband education level, nutritional status of children, frequency of egg consumption, and land size manage by farmers.
\end{abstract}

Keywords: farmer, poverty, gold standard, discriminant analysis, indicator

\section{PENDAHULUAN}

Kemiskinan dalam pengertian konvensional adalah apabila pendapatan suatu komunitas berada di bawah satu garis kemiskinan tertentu (Kurniawan, 2004). Kemiskinan dapat pula dipahami sebagai kekurangan materi, yang biasanya mencakup kebutuhan pangan sehari-hari, sandang, perumahan, dan pelayanan kesehatan. Kemiskinan juga berarti kekurangan kebutuhan sosial, termasuk keterkucilan sosial, ketergantungan, dan ketidakmampuan untuk berpartisipasi dalam kehidupan masyarakat yang layak. Definisi lain yang biasa digunakan adalah menurut European Union bahwa kemiskinan sebagai kondisi seseorang dengan sumberdaya (material, sosial dan budaya) yang sangat terbatas (Anonim, tanpa tahun).

Pada Konferensi PBB terkait Pengembangan Sosial, "Deklarasi Copenhagen" menjelaskan kemiskinan sebagai kondisi yang ditandai oleh kehilangan kebutuhan dasar manusia, termasuk makanan, air minum yang aman,

\footnotetext{
* Penulis untuk korespondensi, Departemen Gizi Masyarakat, FEMA, IPB; Tel: 0251-8628304/8621258: Fax: 0251-8625846/8622276

Email: lpkbiner@yahoo.com
}

fasilitas sanitasi, kesehatan, perumahan, pendidikan dan informasi. Ketika seseorang tidak mampu untuk makan, pergi ke sekolah, atau memiliki akses untuk pelayanan kesehatan, mereka dapat dianggap miskin, tanpa memperhatikan pendapatan mereka (Anonim, 2006).

Menurut data BPS tahun 2006, garis kemiskinan di wilayah Subang adalah sebesar Rp. 210,678/kapita/bulan. Dengan uang senilai tersebut, seseorang dapat memenuhi kebutuhan konsumsi setara dengan 2100 Kalori per kapita per hari, ditambah dengan pemenuhan kebutuhan pokok minimum lainnya, seperti sandang, kesehatan, pendidikan, dan transportasi. Angka garis kemiskinan ini jauh lebih tinggi bila dibanding dengan angka tahun 1996 sebelum krisis ekonomi, yang hanya sekitar Rp. 38,246/kapita/bulan untuk daerah perkotaan dan Rp. 27,413 untuk daerah pedesaan. Garis dan indikator kemiskinan lainnya di Indonesia dikembangkan oleh Sajogyo pada tahun 1975, yang menyatakan bahwa orang miskin memiliki pengeluaran setara dengan $320 \mathrm{~kg}$ beras/kapita/tahun. Lainnya dikembangkan oleh BKKBN (Badan Koordinasi Keluarga Berencana Nasional) yang mengklasifikasikan orang miskin berdasarkan frekuensi konsumsi, sandang, perumahan, dan layanan kesehatan. 
Garis kemiskinan yang ditetapkan BPS maupun Sajogyo diduga terlalu rendah untuk mencukupi kebutuhan hidup minimum bahkan lebih rendah dari garis kemiskinan World Bank US\$1/kapita/hari. Garis kemiskinan yang terlalu rendah tersebut bisa menyebabkan misklasifikasi dan kekeliruan dalam menetapkan jumlah orang miskin secara nasional.

Potret petani Indonesia adalah gambaran keterbelakangan, keterpurukan, ketertinggalan, dan ketidakberdayaan. Di negeri Indonesia yang subur ini tidak banyak petani-pengusaha, tetapi yang banyak adalah buruh tani yang terpinggirkan dan petani gurem yang termarjinalkan. Mereka tidak memiliki posisi tawar untuk mengubah nasib menuju keadaan yang lebih sejahtera. Petani seperti sebuah paradoks: di tengah lahan pertanian yang luas serta didukung kesuburan dan kualitas tanah yang baik, tetap saja nasib petani terpuruk dan tak pernah beranjak dari lingkaran kemiskinan.

Menurut Laporan World Bank yang dikemukakan oleh Sylva dan Bysouth (1992), mayoritas orang miskin tinggal di pedesaan dan hidup dari pertanian. Sebagian besar dari mereka adalah petani kecil, petani marjinal dan buruh tani. Selanjutnya, menurut World Development Report 2003 dalam Sunarti dan Khomsan (2007), penduduk desa miskin yang umumnya petani berhadapan dengan beberapa tantangan yang mempengaruhi potensi pembangunan/perkembangannya yaitu : 1) terbatas atau rusaknya sumberdaya alam, 2) terbatasnya kebijakan dalam pengembangan teknologi produksi, 3) jeleknya infrastruktur (transportasi) dan tidak memadainya perhatian dari institusi pendukung pembangunan (pendidikan, kesehatan, investasi), 4) marjinalnya sosial budaya (hak tanah dan tenure) dan terbatasnya kesempatan ekonomi lokal.

Pada tahun 1984 Indonesia berhasil mencapai swasembada beras dan pada tahun 2004 terjadi surplus beras, namun demikian keberhasilan pembangunan pertanian dalam peningkatan produksi beras belum menunjukkan pengaruh cukup berarti terhadap kesejahteraan para petani sebagai pelakunya. Sensus pertanian 2003 memberikan gambaran keseriusan masalah kemiskinan dan ketidaksejahteraan petani. Data BPS (2003) sebagaimana dikemukakan oleh Krisnamurthi (2006) menunjukkan bahwa dari 24.3 juta rumah tangga pertanian berbasis lahan, 20.1 juta atau sekitar $82.7 \%$ diantaranya masuk dalam kategori miskin. Berdasarkan data tersebut ditambah dengan trend meningkatnya jumlah petani "gurem" dari tahun ke tahun sudah cukup menjadi alasan untuk me- musatkan perhatian pada pengentasan kemiskinan di sektor pertanian dan pedesaan di Indonesia.

Dengan menyadari bahwa sebagian besar keluarga miskin adalah petani, maka penelitian ini menganalisis secara komprehensif berbagai variabel yang menjadi penyebab atau dapat dijadikan indikator kemiskinan petani. Dengan memperhatikan kelemahan-kelemahan garis kemiskinan terdahulu, penelitian ini akan merumuskan New Gold standard of Poverty Line yang terkait dengan indikator pangan, gizi, pertanian, dan sosial ekonomi.

Penelitian ini bertujuan untuk mengembangkan indikator dan gold standard garis kemiskinan baru berdasarkan pangan, gizi, pertanian, dan sosial-ekonomi di antara rumahtangga petani.

\section{METODE PENELITIAN}

\section{Desain, dan Tempat Penelitian}

Penelitian ini menggunakan desain cross sectional dan dilakukan di Kabupaten Subang dengan mengambil dua wilayah yaitu wilayah padi dan wilayah hortikultura. Dari kedua wilayah tersebut diambil contoh rumah tangga petani sejumlah 522 petani. Pengambilan contoh tersebut didasarkan kepada penarikan contoh acak berlapis dengan alokasi proporsional pada tiap wilayah. Data yang dikumpulkan meliputi aspek sosial, pendapatan dan pengeluaran, konsumsi pangan, kesehatan, antropometri dan aspek pertanian.

\section{Tahapan, Pengolahan dan Analisis Data}

Tahapan pengolahan data dimulai dari verifikasi, coding, entry, cleaning dan selanjutnya dianalisis. Untuk mencapai tujuan pertama yaitu menetukan Gold standard Garis kemiskinan dilakukan kegiatan tersebut:

1. Biaya hidup layak minimum dibagi menjadi dua yaitu tetap dan biaya tidak tetap.

2. Biaya tetap adalah biaya yang dipakai bersama oleh anggota rumah tangga, teridentifikasi 41 macam biaya antara lain biaya kompor/tungku, televisi, alat masak, abonemen listrik dan lain-lain.

3. Biaya tidak tetap adalah biaya yang tergantung karakteristik individu misalnya ibu hamil, ibu menyusui, bayi 0-6 bulan dan setersunya sampai manula.

4. Biaya individu terlebih dahulu dibagi dua yaitu biaya pangan dan biaya non pangan. 
5. Biaya pangan dihitung sedemikian rupa sehingga memenuhi kebutuhan gizinya sesuai angka kecukupan gizinya.

6. Biaya non pangan dibagi dalam biaya kesehatan/kebersihan diri, pakaian, perumahan, pendidikan, listrik, komunikasi, hiburan, adat-istiadat, dan lain-lain. Untuk tiap individu teridentifikasi 22 atau lebih jenis biaya non pangan.

Dengan demikian biaya hidup minimum suatu rumah tangga adalah penjumlahan dari biaya tetap ditambah biaya tidak tetap. Biaya rumah tangga dengan jumlah anggota rumahtangga yang sama, biaya hidup minimumnya bisa berbeda karena tergantung pada komposisi anggota rumah tangganya. Biaya Hidup Layak Minimum suatu Rumah tangga (BHLMRT) per bulan dihitung sebagai berikut:

$$
\mathrm{BHLMRT}=\mathrm{C}+\sum_{i=1}^{15} f_{i} B_{i}
$$

Keterangan:

C : biaya hidup layak minimum tetap

fi : jumlah anggota rumah tangga dengan kategori individu ke-I,0,1,2

Bi : biaya hidup layak minimum bagi anggota rumah tangga kategori ke-l, $\mathrm{i}=1$ ibu hamil, $\mathrm{i}=2$ perempuan menyusui, $i=3$ sampai dengan 15 dapat dilihat pada Tabel 5.

Biaya Hidup Layak Minimum suatu Rumah tangga per kapita per bulan (X) dihitung sebagai berikut:

$$
X=\frac{B H M L R T}{\sum_{i=1}^{15} f_{i}}
$$

Karena $\mathrm{X}$ untuk tiap rumah tangga berbeda antara satu dan lainnya maka gold standard garis kemiskinan $\mathrm{g}$ ditentukan berdasarkan kuantil 99\% dengan menggunakan pendekatan sebaran normal baku Z bagi X sebagai berikut:

Gold standard garis kemiskinan didasarkan kepada sebaran garis kemiskinan rumahtangga (Rp/kapita/bulan). Katakanlah X adalah garis kemiskinan rumah tangga yang diasumsikan menyebar normal dengan mean $\mu$ dan standard deviasi $\sigma$. Gold standard garis kemiskinan yang lebih tinggi dari garis kemiskinan rumah tangga sehingga ada $(1-$ a) $\times 100 \%$ rumah tangga yang lebih kecil dari gold standard garis kemiskinan dirumuskan sebagai berikut:

$\mathrm{P}\left(x \leq g_{\alpha}\right)=1-\alpha, \quad \mathrm{P}\left(\frac{x-\mu}{\sigma} \leq \frac{g_{\alpha}-\mu}{\sigma}\right)=1-\alpha$,
$\mathrm{P}\left(\mathrm{Z} \leq \mathrm{Z}_{\alpha}\right)=1-\alpha \quad \frac{g_{\alpha}-\mu}{\sigma}=\mathrm{Z} \alpha$,

$g_{\alpha}=\mu+\mathrm{Z}_{\alpha} \sigma$

Keterangan:

$X$ : Garis kemiskinan rumah tangga

$\mathrm{g}_{\mathrm{a}}$ : Gold standard garis kemiskinan sehingga $P\left(x \leq g_{\alpha}\right)=1-\alpha$

$\mu$ : Rata-rata garis kemiskinan rumah tangga

$\sigma$ : Standard deviasi garis kemiskinan rumahtangga

a : Peluang garis kemiskinan yang lebih besar dari gold standard garis kemiskinan

$\mathrm{Z}$ : Peubah acak normal baku $0<\alpha<1$

Agar garis kemiskinan rumah tangga $x$ hanya sedikit yang di atas gold standard garis kemiskinan $g_{a}$ maka (1- a) $\times 100$ harus relatif besar atau a\% relatif kecil. Katakanlah (1- a) $x$ $100=99 \%$, maka berarti hanya ada $a=1 \%$ rumah tangga yang sebenarnya miskin tapi oleh gold standard garis kemiskinan dinyatakan tidak miskin. Untuk 99\% garis kemiskinan maka gold standard garis kemiskinannya:

$$
g_{0.01}=\mu+\mathrm{Z}_{0.01} \sigma
$$

Agar nilai gold standard garis kemiskinan g lebih stabil (dalam artian gram emas) maka g dikonversi ke harga emas murni dalam gram sehingga menjadi: $\mathrm{g}^{*}=\mathrm{g} / 200,000$ gram (harga emas murni per gram saat survey sebesar Rp. 200,000/gram).

Tujuan kedua dicapai dengan cara menghitung pendapatan per kapita per bulan setiap rumah tangga lalu menentukan status kemiskinannya denga garis kemiskinan Sajogyo, BKKBN, BPS, Bank Dunia \$1 dan Bank Dunia \$2. Garis kemiskinan Sajogyo dihitung berdasarkan $320 \mathrm{~kg}$ beras per kapita per tahun dengan harga beras dianggap Rp 6,500/kg. Untuk garis kemiskinan BKKBN dilakukan dengan cara memberikan status miskin pada rumah tangga apabila rumah tangga tersebut termasuk pra sejahtera atau sejahtera 1 dan status tidak miskin apabila rumah tangga tersebut tergolong sejahtera 2, 3 atau 3+. Garis kemiskinan BPS untuk kabupaten Subang saat survei sebesar Rp. 210,678/kapita/bulan. Garis kemiskinan Bank Dunia \$1 dan \$2 menggunakan nilai tukar dolar terhadap rupiah sebesar Rp. 9,500, sesuai nilai tukar dolar yang berlaku saat survei. Selanjutnya dihitung persentase yang miskin untuk setiap garis kemiskinan tersebut. Untuk membedakan apakah garus kemiskinan yang lama berbeda atau tidak dengan $\mathrm{X}$ maka digunakan uji proporsi dengan pendekatan sebaran normal baku. 
Untuk mencapai tujuan 3 yaitu mencari indikaktor yang dapat digunakan untuk menentukan status kemiskinan rumah tangga tanpa menghitung pendapatan digunakan analisis diskriminan dengan fungsi sebagai berikut:

$$
d(x)=d_{1}(x)-d_{2}(x)
$$

Jika $\mathrm{d}(\mathrm{x})>0$ maka rumah tangga disebut miskin sebaliknya tidak miskin

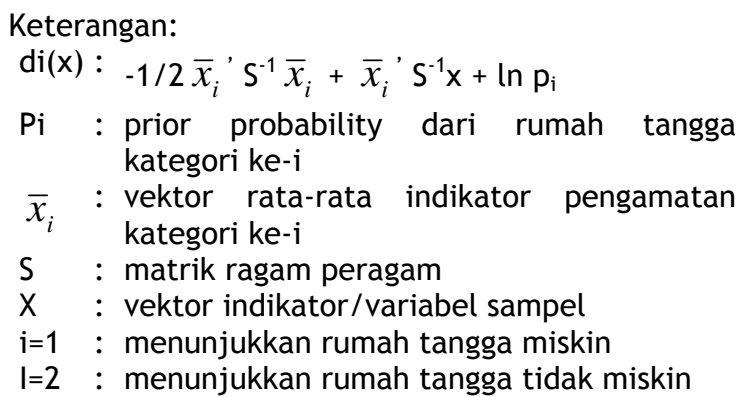

\section{HASIL DAN PEMBAHASAN}

\section{Gold Standard Garis Kemiskinan}

Konsep dasar garis kemiskinan (poverty line) selama ini ditetapkan berdasarkan besarnya pengeluaran untuk dapat memenuhi kebutuhan dasar seseorang agar dapat hidup dengan normal. Garis kemiskinan dinyatakan dalam satuan pendapatan per kapita per bulan. Menurut laporan PBB terdapat 12 komponen kebutuhan dasar yaitu (1) kesehatan, (2) makanan dan gizi, (3) pendidikan,(4) kondisi pekerjaan, (5) situasi kesempatan kerja, (6) konsumsi dan tabungan, (7) transportasi, (8) perumahan, (9) sandang, (10) rekreasi dan hiburan, (11) jaminan sosial, dan (12) kebebasan.

Kriteria rumah tangga miskin yang ditetapkan oleh Biro Pusat Statistik (BPS) didasarkan pada besarnya rupiah yang dibelanjakan untuk memenuhi kebutuhan minimum pangan dan non-pangan per kapita per bulan. Komoditas pangan terpilih terdiri dari 52 macam, sedangkan komoditas nonpangan terdiri dari 27 jenis untuk kota dan 26 jenis untuk desa.

Gold standard garis kemiskinan untuk wilayah padi dan hortikultura di kabupaten Subang (Rp/kapita/bulan) seperti tercantum dalam Tabel 1 selanjutnya ditentukan dengan dasar 99\% kuantil, seperti yang dijelaskan dalam metode penentuan gold standard garis kemiskinan $\mathrm{g}_{\alpha}=\mathrm{g}_{0.01}$, sehingga diperoleh garis kemiskinan sebesar Rp. 457,558 per kapita per bulan. Apabila dinyatakan dalam mas murni dengan harga pada saat survei yaitu sebesar Rp. 200,000/gram maka diperoleh gold stan- dard garis kemiskinan sebesar 2.29 gram/ kapita/bulan.

Komponen biaya hidup minimum terdiri atas seluruh biaya untuk memenuhi kebutuhan hidup layak termasuk kebutuhan pangan yang memenuhi standar kecukupan gizi, dan kebutuhan nonpangan seperti sandang, perumahan, penerangan (listrik atau lainnya), bahan bakar, komunikasi, hiburan, kegiatan keagamaan atau sosial, seluruh peralatan rumah tangga yaitu peralatan dapur, peralatan kamar mandi, peralatan kebersihan, peralatan ibadah, dan peralatan furniture.

Tabel 1. Statistik Biaya Hidup Minimum dan Gold standard Garis Kemiskinan (Rp/Kap/Bln)

\begin{tabular}{lccc}
\hline \multicolumn{1}{c}{ Wilayah } & Rata-rata & Sd & $\begin{array}{c}\text { Gold Standard } \\
\text { Garis Kemiskian }\end{array}$ \\
\hline - Padi & 390,481 & 33,733 & 469,079 \\
- Hortikultura & 362,014 & 30,056 & 432,044 \\
- Total & 376,248 & 34,952 & 457,558 \\
\hline
\end{tabular}

Dalam merumuskan biaya hidup minimum telah dibuat daftar kebutuhan hidup individu yang mencakup 19 jenis pangan (Tabel 2) dan 44 jenis kebutuhan nonpangan (Tabel 3). Selain itu, dibuat pula kebutuhan nonpangan rumah tangga, kebutuhan ini dapat digunakan bersama-sama oleh sekelompok orang yang hidup dalam satu rumah. Tabel 4 menunjukkan 41 jenis kebutuhan nonpangan rumah tangga.

Tabel 2. Jenis Kebutuhan Pangan untuk Penentuan Biaya Hidup Minimum (Individu)

\begin{tabular}{llll}
\hline No & \multicolumn{1}{c}{ J enis Pangan } & No & \multicolumn{1}{c}{ J enis Pangan } \\
\hline 1 & Nasi & 11 & Susu bubuk \\
2 & Bubur (bayi) & 12 & $\begin{array}{l}\text { Singkong, ubi jalar, } \\
\text { talas, dll }\end{array}$ \\
3 & Daging ayam & 13 & Minyak goreng \\
4 & Telur & 14 & Gula \\
5 & Ikan & 15 & Garam \\
6 & Tahu & 16 & Bawang merah \\
7 & Tempe & 17 & Bawang putih \\
8 & Kacang-kacangan & 18 & Cabe, jahe, kunyit, dll \\
9 & Bayam/kangkung & 19 & Teh \\
10 & $\begin{array}{l}\text { Mangga, jeruk, } \\
\text { pisang, dll }\end{array}$ & & \\
\hline
\end{tabular}


Tabel 3. Jenis Kebutuhan Nonpangan untuk Penentuan Biaya Hidup Minimum (Individu)

\begin{tabular}{|c|c|c|c|}
\hline No & J enis Non Pangan & No & Jenis Non Pangan \\
\hline 1 & $\begin{array}{l}\text { Biaya } \\
\text { pembuatan/sewa } \\
\text { rumah }\end{array}$ & 22 & Bedak \\
\hline 2 & Tanah & 23 & Sisir rambut \\
\hline 3 & Pakaian wanita (luar) & 24 & Lipstik \\
\hline 4 & $\begin{array}{l}\text { Pakaian laki-laki } \\
\text { (luar) }\end{array}$ & 25 & $\begin{array}{l}\text { Minyak kayu } \\
\text { putih\&telon }\end{array}$ \\
\hline 5 & Daster & 26 & Baby oil \\
\hline 6 & Celana dalam & 27 & Perlak \\
\hline 7 & $\mathrm{BH}$ & 28 & Pengobatan \\
\hline 8 & Kaos dalam & 29 & $\begin{array}{l}\text { Pemeriksaan } \\
\text { kesehatan }\end{array}$ \\
\hline 9 & Mukena & 30 & Transportasi \\
\hline 10 & Sarung & 31 & Biaya perkawinan \\
\hline 11 & Sandal selop & 32 & $\begin{array}{l}\text { Transportasi \& uang } \\
\text { saku }\end{array}$ \\
\hline 12 & Sandal jepit & 33 & Alat tulis \\
\hline 13 & $\begin{array}{l}\text { Kaos kaki \&sarung } \\
\text { tangan (bayi) }\end{array}$ & 34 & Buku pelajaran \\
\hline 14 & Tempat Tidur & 35 & Tas sekolah \\
\hline 15 & Kasur & 36 & Seragam sekolah \\
\hline 16 & Seprei & 37 & Kaos kaki sekolah \\
\hline 17 & Bantal & 38 & Sepatu sekolah \\
\hline 18 & Sabun mandi & 39 & Ikat pinggang \\
\hline 19 & Sabun cuci & 40 & Gordyn \\
\hline 20 & Shampoo & 41 & Selimut \\
\hline 21 & Pasta gigi & 42 & Dompet \\
\hline 22 & Sikat gigi & 44 & Mainan bayi \\
\hline
\end{tabular}

Tabel 4. Jenis Kebutuhan Nonpangan untuk Penentuan Biaya Hidup Minimum (Rumah tangga)

\begin{tabular}{|c|c|c|}
\hline No & J enis Pangan & J enis Pangan \\
\hline 1 & Instalasi listrik & 22 Pisau \\
\hline 2 & Iuran listrik (abonemen) & 23 Parutan kelapa \\
\hline 3 & Lampu & 24 Serok \\
\hline 4 & Bahan bakar (minyak tanah) & 25 Centong \\
\hline 5 & $\mathrm{HP}$ & 26 Susuk \\
\hline 6 & Pulsa & 27 Ember \\
\hline 7 & Hiburan (TV warna 15 inci) & 28 Gayung \\
\hline 8 & Sumbangan Pernikahan & 29 Sikat pakaian \\
\hline 9 & Sumbangan Khitanan & 30 Sikat kamar mandi \\
\hline 10 & Sumbangan Kematian & 31 Sapu lidi \\
\hline 11 & Sumbangan & 32 Sapu ijuk \\
\hline 12 & Kompor & 33 Lap \\
\hline 13 & Penggorengan & 34 Pembuatan instalasi air \\
\hline 14 & Panci & 35 Tikar \\
\hline 15 & Dandang/langseng & 36 Kitab suci \\
\hline 16 & Sendok & 37 Kursi dan meja makan \\
\hline 17 & Piring & 38 Kursi dan meja tamu \\
\hline 18 & Gelas & 39 lemari pakaian \\
\hline 19 & Wadah nasi & 40 Payung \\
\hline 20 & Rak piring & 41 Setrikaan \\
\hline 21 & Cobek & \\
\hline
\end{tabular}

Berbagai daftar kebutuhan pangan dan nonpangan sebagaimana tercantum dalam tabel-tabel tersebut diaplikasikan pada $16 \mathrm{ke}$ lompok anggota rumah tangga (Tabel 5), kemudian ditentukan rata-rata biaya hidup minimum untuk tiap rumah tangga responden.

Perhitungan kebutuhan hidup minimum dibedakan menurut kategori umur, dan jenis kelamin dan keadaan fisiologis. Proses perhitungan biaya hidup minimum dengan memperhatikan segala macam kebutuhan pangan dan nonpangan, serta pembagian kelompok umur, jenis kelamin, ataupun keadaan fisiologis telah dilakukan dengan teliti dan cukup terinci, sehingga garis kemiskinan yang dihasilkan dapat dianggap sebagai gold standard.

Tabel 5 menunjukkan bahwa biaya hidup minimum untuk perempuan hamil adalah paling besar yaitu Rp. 439,907/bulan untuk di wilayah padi, sedangkan untuk wilayah hortikultura adalah Rp. 401,284/bulan. Hal ini terjadi karena ibu hamil membutuhkan biaya pemeriksaan kehamilan termasuk biaya transportasi untuk ke puskesmas atau ke bidan; selain itu kebutuhan pangan yang memenuhi standar gizi ibu hamil lebih mahal dibandingkan mereka yang tidak hamil. Biaya hidup minimum yang paling kecil adalah untuk bayi berusia 0 - 6 tahun, karena bayi berusia 0 - 6 tahun masih menyusu sehingga tidak membutuhkan biaya pangan. Dalam hal ini diasumsikan bayi disusui secara eksklusif dari ASI ibunya. Biaya individu lain, sedikit berbeda antara wilayah padi dan hortikultura (Tabel 5).

\section{Perbandingan Garis Kemiskinan}

Garis kemiskinan Sajogyo adalah garis kemiskinan terkecil dibandingkan garis kemiskinan BPS atau Bank Dunia yaitu Rp. 173,333/ kapita/bulan. Garis kemiskinan BPS adalah garis kemiskinan terendah kedua yaitu sebesar Rp. 210,678/kapita/bulan. Kriteria kesejahteraan rumah keluarga menurut BKKBN tidak dapat ditentukan besaran rupiahnya karena bersifat kualitatif. Apabila digunakan untuk menentukan kemiskinan rumah tangga maka kriteria BKKBN ini cukup dekat dengan gold standard. Garis kemiskian Bank Dunia (US\$1) adalah garis kemiskinan terendah ketiga yaitu sekitar Rp. 321,000/kapita/bulan. Garis kemiskinan Bank Dunia (US\$2) adalah garis kemiskinan tertinggi yaitu sekitar Rp. 642,000/kapita/ bulan dan berada di atas gold standard.

Garis kemiskinan BPS, BKKBN, Sajogjo, dan Bank Dunia (US\$1) semuanya berada di bawah gold standard hasil penelitian ini. Sementara garis kemiskinan Bank Dunia (US\$2) ber- 
ada di atas gold standard seperti ditunjukkan oleh kolom total Tabel 6. Semua garis kemiskinan menyimpang di atas $9 \%$ baik untuk rumah tangga yang seharusnya termasuk miskin ataupun yang seharusnya tidak miskin.

\section{Indikator Kemiskinan}

Berdasarkan hasil analisis diskriminan terhadap berbagai aspek sosial-ekonomi, pertanian, konsumsi pangan, status gizi dan kesehatan diperoleh lima variabel yang dapat menjadi indikator kemiskinan petani di wilayah padi maupun hortikultura yaitu jumlah anggota rumah tangga (orang), pendidikan formal suami (tahun), nilai minimum Z-skor tinggi menurut umur anak (Z-skor TB/U), frekuensi konsumsi telur (kali/minggu) dan total luas lahan $\left(\mathrm{m}^{2}\right)$ seperti dapat dilihat pada Tabel 7. Fungsi diskriminan untuk rumah tangga miskin dinotasikan oleh fungsi $\mathrm{d} 1\left(\mathrm{x}_{1}, \mathrm{x}_{2}, \mathrm{x}_{3}, \mathrm{x}_{4}, \mathrm{x}_{5}\right)$, sedangkan untuk rumah tangga tidak miskin dinotasikan oleh fungsi $d 2\left(x_{1}, x_{2}, x_{3}, x_{4}, x_{5}\right)$. Suatu rumah tangga disebut miskin apabila fungsi $d=d 1$ $\mathrm{d} 2>0$. Dari hasil analisis diketahui bahwa fungsi diskriminan d memiliki keakurasian sebesar $84.01 \%$.

Tabel 5. Rincian Biaya Hidup Minimum (Rp/kapita/bulan)

\begin{tabular}{|c|c|c|c|}
\hline \multirow{2}{*}{ No } & \multirow{2}{*}{ Kelompok Umur } & \multicolumn{2}{|c|}{ Wilayah } \\
\hline & & Padi & Hortikultura \\
\hline & Kebutuhan Rumah tangga & 213276 & 214680 \\
\hline 1 & Perempuan Hamil & 439907 & 401284 \\
\hline 2 & Perempuan Menyusui & 367982 & 363092 \\
\hline 3 & Bayi Laki-laki/Perempuan (0-6 bulan) & 53482 & 53482 \\
\hline 4 & Bayi Laki-laki/Perempuan (7-12 bulan) & 200295 & 200295 \\
\hline 5 & Balita Laki-laki/Perempuan (1-5 tahun) & 311863 & 285029 \\
\hline 6 & Anak Perempuan (6-13 tahun) & 290767 & 290628 \\
\hline 7 & Anak Laki-laki (6-13 tahun) & 292353 & 311783 \\
\hline 8 & Remaja Perempuan (14-17 tahun) & 375302 & 370631 \\
\hline 9 & Remaja Laki-laki (14-17 tahun) & 371735 & 395266 \\
\hline 10 & Dewasa Perempuan Sudah Menikah (18-65 tahun) & 318583 & 284731 \\
\hline 11 & Dewasa Perempuan Belum Menikah (18-65 tahun) & 321653 & 290579 \\
\hline 12 & Dewasa Laki-laki Sudah Menikah (18-65 tahun) & 317632 & 296777 \\
\hline 13 & Dewasa Laki-laki Belum Menikah (18-65 tahun) & 323773 & 305549 \\
\hline 14 & Lansia Perempuan (>65 tahun) & 318539 & 284394 \\
\hline 15 & Lansia Laki-laki (>65 tahun) & 311097 & 253598 \\
\hline
\end{tabular}

Tabel 6. Sebaran Rumah tangga menurut Gold standard atau Garis Kemiskinan

\begin{tabular}{|c|c|c|c|c|}
\hline \multirow{2}{*}{ Status } & \multirow{2}{*}{ Kriteria } & \multicolumn{3}{|c|}{ Persentase } \\
\hline & & Padi & Hortikultura & Total \\
\hline \multirow{6}{*}{ Miskin } & - Gold Standard & 59.77 & 76.63 & 68.20 \\
\hline & - BPS & 36.02 & 52.11 & 44.06 \\
\hline & - BKKBN & 74.71 & 44.44 & 59.58 \\
\hline & - Sajogjo & 29.12 & 42.53 & 35.82 \\
\hline & - Bank Dunia (US\$1) & 49.04 & 65.90 & 57.47 \\
\hline & - Bank Dunia (US\$2) & 73.56 & 85.82 & 79.69 \\
\hline \multirow{6}{*}{ Tdk Miskin } & - Gold Standard & 40.23 & 23.37 & 31.80 \\
\hline & - BPS & 63.98 & 47.89 & 55.94 \\
\hline & - BKKBN & 25.29 & 55.56 & 40.42 \\
\hline & - Sajogjo & 70.88 & 57.47 & 64.18 \\
\hline & - Bank Dunia (US\$1) & 50.96 & 34.10 & 42.53 \\
\hline & - Bank Dunia (US\$2) & 26.44 & 14.18 & 20.31 \\
\hline
\end{tabular}

Tabel 7. Fungsi Diskriminan di Wilayah Padi dan Hortikultura

\begin{tabular}{lccc}
\hline \multirow{2}{*}{ Variabel } & \multicolumn{3}{c}{ Fungsi Diskriminan } \\
\cline { 2 - 4 } & Miskin & Tidak Miskin & Fungsi \\
\cline { 2 - 4 } & $\mathbf{d 1}$ & $\mathbf{d 2}$ & $\mathbf{d = d 1 - d 2}$ \\
\hline Konstanta & -10.7511 & 1.74862 \\
X $_{1}=$ Jumlah anggota rumah tangga & 3.6768 & 3.28594 & 0.39086 \\
X $_{2}=$ Pendidikan suami (tahun) & 0.75085 & 0.85593 & -0.10508 \\
X $_{3}=$ Min Zskor TB/U anak & -0.17909 & 0.02588 & -0.20497 \\
X $_{4}=$ Frekuensi konsumsi telur (kali/minggu) & 0.36343 & 0.55831 & -0.19488 \\
X $_{5}=$ Total ukuran lahan (m2) & -0.0000434 & 0.0003198 & -0.0003632 \\
\hline
\end{tabular}




\section{KESIMPULAN}

Dari hasil penelitian telah dapat ditentukan gold standard garis kemiskinan sebesar Rp. 457,558/kapita/bulan (US \$1.61/kapita/ bulan) atau setara dengan 2.29 gram mas murni per kapita per bulan.

Garis kemiskinan Sajogyo, BKKBN, BPS, Bank Dunia \$1 berada di bawah gold standard garis kemiskinan, sedangkan garis kemiskinan Bank Dunia \$2 berada di atas gold standard garis kemiskinan

Fungsi diskriminan dengan indikator gabungan yang didsarkan pada gold standard hidup layak minimum memiliki akurasi sebesar 84.01\% dan dapat digunakan untuk mengidentifikasi suatu rumah tangga apakah miskin atau tidak msikin. Fungsi ini lebih sederhana daripada cara BKKBN yang memiliki banyak indikator.

\section{UCAPAN TERIMA KASIH}

Penelitian ini merupakan sebagian dari proyek riset yang dibiayai oleh Neys van Hoogstraten Foundation (NHF) dan diketuai oleh Dr. Nani Sufiani Suhanda. Untuk itu diucapkan terima kasih kepada NHF selaku penyandang dana.

\section{DAFTAR PUSTAKA}

Anonim. (tanpa tahun). Defining Poverty. Anglicare.Asn.Au.
Anonim. 2006. A Dollar a day: Poverty Overview. http://library.thinkquest.org/ 05aug/00282/over_whatis.htm (1 jan 2008).

BPS (Central Bureau of Statistics). 2006. Poverty Level in Indonesia Year 20052006. Official News of Statistics, No. 47/IX/1 September 2006, page 1. www.ypr.or.id.

BPS (Central Bureau of Statistics). 2003. Statistik Indonesia (Statistictical Year Book of Indonesia). BPS, Jakarta.

Khomsan A \& Sukandar D. 1996. Studi Konsumsi Pangan sebagai Indikator Kemiskinan. Jurusan Gizi Masyarakat dan Sumberdaya Keluarga, Fakultas Pertanian, IPB, Bogor.

Krisnamurthi B. 2006. Agriculture Revitalization, A Historical Consequence and Future Demand. In Agriculture Revitalization and Cultural Dialogue. Kompas Publisher, Jakarta.

Kurniawan RC. 2004. Poverty Pathology "An Ironic of A Country". Department of Governmental Science - Faculty of Social and Politics Sciences, UNILA, Lampung.

Sylva ED. \& Bysouth K. 1992. Poverty Alleviation through Agricultural Projects. The World Bank, Washington, D.C.. 